Emerson A. Moffitt MD, Dhun H. Sethna MD, Richard J. Gary MD, Marjorie J. Raymond RN, Jack M. Matloff MD, John A. Bussell MD

\title{
Nitrous Oxide added to Halothane Reduces Coronary Flow and Myocardial Oxygen Consumption in Patients with Coronary Disease
}

The haemodynamic and myocardial metabolic effects of adding 50 per cent nitrous oxide to 0.5 per cent halothane were studied in 13 patients, before the surgical incision for coronary artery vein grafts. Cardiac output and coronary sinus blood flow were determined by thermodilution, along with haemodynamic measurements. Measurements 15 minutes after addition of nitrous oxide revealed a significant decrease in heart rate, arterial pressure, cardiac index, coronary sinus blood flow and myocardial oxygen consumption. There was a significan increase in coronary sinus lactate content, and a signifcant decrease, from 27 to 11 per cent, in myocardial lactate extraction. We conclude that these circulatory changes were likely to be due to a depression of ventricular function by the nitrous axide. The myocardia of these patients with severe coronary disease were becoming globally ischaemic while they were receiving 50 per cent axygen, in the presence of hypotension. Nitrous oxide should be urned off when hypoten. sion vecurs in coronary patients.

\section{Key Words}

HEAkT: coronary disease, myocardial function, anaesthetics. ANAESTHETICS, GASES: nitrous oxide, BLOOD PRESSURE: drug effects.

From the Department of Anaesthesia, Dalhousie University, Halifax, Nova Scotia and the Departments of Anaesthesiology and Cardiovascular Surgery, Cedars. Sinai Medical Center, Los Angeles, California.

Address correspondence to: E. A. Moffitt MD, Sir Charles Tupper Medical Building. University Avenue, Halifax, Nova Scotia B3H $4 \mathrm{H} 7$.
Until a decade or so ago, nitrous oxide $\left(\mathrm{N}_{2} \mathrm{O}\right)$ was considered to have no appreciable circulatory ef fects, providing hypoxia was not present. In 1970 Smith and co-workers ${ }^{1}$ found in healthy volunteers that adding 70 per cent $\mathrm{N}_{2} \mathrm{O}$ to stable concentrations of halothane caused elevated systemic vascular resistance and arterial pressure, but no change in cardiac output. Then Eisele and $\mathrm{Smith}^{2}$ reported in healthy man, that 40 per cent $\mathrm{N}_{2} \mathrm{O}$ depressed myocardial function, but increased systemic resistance, which maintained arterial pressure. In 1980 , Wynne $e t a l .^{3}$ assessed the effects of 50 per cent $\mathrm{N}_{2} \mathrm{O}$ on left ventricular function in patients with coronary disease. They found a small decrease in heart rate and cardiac index and no change in blood pressure. In patients with coronary disease, addition of $\mathrm{N}_{2} \mathrm{O}$ to both morphine ${ }^{4}$ and fentanyl ${ }^{5}$ depresses left ventricular function, with reduced blood pressure, stroke work and cardiac output. Given with fentanyl, 60 per cent $\mathrm{N}_{2} \mathrm{O}$ also slowed the heart rate. ${ }^{5}$

Hence we studied the effects of adding 50 per cent $\mathrm{N}_{2} \mathrm{O}$ to 0.5 per cent halothane in oxygen, in 13 patients anaesthetized for coronary artery bypass grafting (CABG). Cardiac function and haemodynamics were studied plus myocardial energy metabolism, including coronary sinus blood flow (CBF), myocardial oxygen consumption $\left(\mathrm{MVO}_{2}\right)$ and lactate extraction as indicators of oxygen balance.

This investigation was part of a larger study of 30 patients which extended from before induction of anaesthesia, through operation for CABG and for 
24 hours postoperatively. ${ }^{6}$ All protocols were approved by the Human Subjects Committee of Cedars-Sinai Medical Center. Signed informed consent was obtained. All 13 patients had serious coronary disease, but none had depressed ventricular function (all ejection fractions above 0.5 ). Their mean age was 58.6 years and mean weight was $79 \mathrm{~kg}$. Their functional status by New York Heart Association was: Class II - 7, IlI - 4, IV - 2 . Six patients were taking propranolol and nine had previous myocardial infarction. They subsequently received a mean of 3.8 vein grafts. None of the patients had a perioperative infarction.

\section{Methods}

The $\mathrm{N}_{2} \mathrm{O}$ study was done after endotracheal intubation but before the surgical incision was made. Before induction of anaesthesia, after secobarbital premedication (mean dose: $210 \mathrm{mg}$ ) and lidocaine infiltration, a radial artery cannula was inserted, plus two thermodilution catheters, both via the right internal jugular vein. In addition to the usual pulmonary arterial catheter ${ }^{7}$ (Edwards Co.) another special preshaped eight $\mathrm{Fr}$ thermistor-equipped catheter (Wilton-Webster Labs) was placed in the midcoronary sinus, aided by fluoroscopy. The latter catheter ${ }^{8}$ measures total coronary sinus blood flow which represents virtually all of left coronary arterial flow.

Induction of anaesthesia in these 13 patients had been initiated with a small dose of thiopental (mean $=133 \mathrm{mg}$ ) followed by halothane-oxygen for a mean of 14.6 minutes before intubation. After intubation, when circulatory dynamics had returned to levels present when awake (mean arterial pressure $95 \mathrm{mmHg}$, mean cardiac index $2.59 \mathrm{~L} / \mathrm{min} / \mathrm{m}^{2}$ ) and with 0.5 per cent halothane being given, control measurements were done. At a mean of 14.2 minutes after intubation, 50 per cent $\mathrm{N}_{2} \mathrm{O}$ was added to the inspired mixture with controlled ventilation. The second series of measurements was after 15 minutes of $\mathrm{N}_{2} \mathrm{O}$ administration.

Each series consisted of measuring cardiac output (duplicate), total CBF, arterial and central pressures and sampling arterial and coronary sinus blood for hemoglobin, oxygen and lactate contents. Haemodynamic indices were calculated using standard formulas. ${ }^{9}$ Haemoglobin and oxygen saturation was determined by co-oximetry (IL Co-oximeter, Model 282) and oxygen content calculated as: $\mathrm{Hb} \times \mathrm{O}_{2}$ per cent saturation $\times 1.34$, for $\mathrm{ml} \mathrm{O}_{2} / 100$ $\mathrm{ml}$ of blood. $\mathrm{MVO}_{2}$ in $\mathrm{ml} /$ minute was calculated as: CBF (ml/min) $\times$ ART-CS difference of content of oxygen, in $\mathrm{ml} / 100 \mathrm{ml}$. Lactate measurement was by a modification of the Marbach method. ${ }^{10}$ The myocardial lactate extraction ratio was calculated from the formula ART-CS/Art. $\times 100$, where ART and $\mathrm{CS}$ are the concentrations of lactate in $\mathrm{mmol} / \mathrm{L}$, in arterial and coronary sinus blood.

The Wilcoxon paired rank test was employed for statistical evaluations.

\section{Results}

With constant mechanical ventilation, before and during $\mathrm{N}_{2} \mathrm{O}$ administration, mean $\mathrm{PaCO}_{2}$ was $39 \pm$ 5 and $35 \pm 6 \mathrm{mmHg}$ and mean $\mathrm{pH}$ was $7.42 \pm 0.06$ and 7.46 \pm 0.06 . Mean $\mathrm{PaO}_{2}$ on 50 per cent $\mathrm{N}_{2} \mathrm{O}$ was $170 \pm 41 \mathrm{mmHg}$ compared to $350 \pm 60$ before it. The mean bicarbonate concentration, at $25 \pm 1.9$, did not change.

TABLE t: After 15 minutes of $\mathrm{N}_{2} \mathrm{O}$, there were highly significant decreases in heart rate, mean arterial pressure and hence rate-pressure product. Cardiac index also fell 18 per cent $(p<0.003)$, without change in stroke volume. The 35 per cent reduction ( $p<0.003$ ) in mean stroke work was due to the fall in blood pressure. While right atrial pressure was unchanged and pulmonary capillary wedge pressure showed a statistically non-significant decrease, mean pulmonary arterial pressure did decrease significantly $(p<0.01$ ). Pulmonary vascular resistance was unchanged but systemic vascular resistance was reduced significantly ( $p<$ $0.01)$.

TABLE II: Mean total CBF had a highly significant decrease from 96 to $61 \mathrm{ml} /$ minute $(p<0.002)$. Along with the small but statistically significant decrease in oxygen content of coronary sinus blood, this produced a 35 per cent reduction in calculated $\mathrm{MVO}_{2}(\mathrm{p}<0.002)$. With no alteration in lactate content of arterial blood, a 19 per cent increase occurred in lactate content of coronary sinus blood ( $p<0.04$ ). This was reflected by a change from 27 to 11 per cent in mean lactate extraction by the ventricular muscle.

A reduction in lactate extraction occurred in nine of the 13 patients. In two patients, changes from 32 and three per cent extraction, to 52 and 62 per cent lactate production, respectively, occurred as CBF fell 44 and 49 per cent in each. No alteration in ST segment configuration was seen during administration of the $\mathrm{N}_{2} \mathrm{O}$. 
TABLE I Haemodynamic Data

\begin{tabular}{|c|c|c|c|}
\hline & Contra' & On $50 \% \mathrm{~N}_{2} \mathrm{O}$ & $p$ Volue \\
\hline Rate beats/minute & $72 \pm 13^{*}$ & $64 \pm 9$ & $<0.003$ \\
\hline Mean arterial pressure $\mathrm{mmHg}$. & $101 \pm 16$ & $74 \pm 15$ & $<0,002$ \\
\hline Rate-pressure product & $10,373 \pm 2484$ & $6650 \pm 1694$ & $<0.002$ \\
\hline Cardiac index L/minute $/ \mathrm{M}^{2}$ & $2.48 \pm 0.5$ & $2.03 \pm 0.4$ & $<0.003$ \\
\hline \multicolumn{4}{|l|}{ Stroke volume index } \\
\hline $\mathrm{ml} / \mathrm{beat} / \mathrm{M}^{2}$ & $34.9 \pm 7$ & $32.1 \pm 5$ & N.S. \\
\hline Stroke work index $\mathrm{GmM} / \mathrm{M}^{2}$ & $54 \pm 10$ & $35 \pm 10$ & $<0.003$ \\
\hline Right atrial pressure mmHg & $8 \pm 4$ & $8 \pm 3$ & N.S. \\
\hline $\begin{array}{l}\text { Mean pulmonary arterial } \\
\text { pressure mmHg }\end{array}$ & $18 \pm 4$ & $15 \pm 3$ & $<0.01$ \\
\hline $\begin{array}{l}\text { Pulmonary capillary wedge } \\
\text { pressure } \mathrm{mmHg}\end{array}$ & $16 \pm 5$ & $13 \pm 3$ & N.S. \\
\hline \multicolumn{4}{|l|}{ Systemic vascular resistance } \\
\hline Dynes $\cdot \mathrm{Sec} \cdot \mathrm{Cm}^{-3}$ & $1671 \pm 552$ & $1412 \pm 481$ & $<0.01$ \\
\hline Pulmonary vascular tesistance & & & \\
\hline Dynes $\cdot \mathrm{Sec}_{\mathrm{ec}} \cdot \mathrm{Cm}^{-5}$ & $318 \pm 119$ & $326 \pm 74$ & N.S. \\
\hline
\end{tabular}

$n=13$. *Mean $~$ S.D. N.S. - Not Significant.

TABLE II Myocardial Blood Flow and Metabolism

\begin{tabular}{lccl}
\hline & Control & On $50 \% \mathrm{~N}_{2} \mathrm{O}$ & p Value \\
\hline Coronary blood flow ml/minute & $96 \pm 32^{*}$ & $61 \pm 18$ & $<0.002$ \\
Coronary sinus $\mathrm{O}_{2}$ content ml'lo0 ml & $7.0 \pm 1.2$ & $6.5 \pm 1.3$ & $<0.02$ \\
Myocardial $\mathrm{VO}_{2}$ ml/minute & $8.2 \pm 3.3$ & $5.3 \pm 1.9$ & $<0.002$ \\
Arterial lactate mmoliL & $1.20 \pm 0.37$ & $1.18 \pm 0.42$ & N.S. \\
Coronary sinus lactate mmolL & $0.85 \pm 0.21$ & $1.01 \pm 0.37$ & $<0.01$ \\
Myocardial lactate extraction \% & $27 \pm 13$ & $11 \pm 32$ & $<0.04$ \\
\hline
\end{tabular}

$n=13$. *Mean \pm S.D. N.S. - Not Significant.

\section{Discussion}

The cardiovascular effects of $\mathrm{N}_{2} \mathrm{O}$ depend on several factors, including the model studied (animal or human), presence of coronary disease, when one looks for effects, how much $\mathrm{N}_{2} \mathrm{O}$ is given and importantly, whether other agents are also given. In the dog, Thorburne et al. " report that with 65-70 per cent $\mathrm{N}_{2} \mathrm{O}$ for 15 minutes, cardiac output decreased, but systemic resistance and atrial pressure increased. Heart rate, arterial pressure, coronaty blood flow and resistance and $\mathrm{MVO}_{2}$ were unchanged. In patients with coronary disease, 50 per cent $\mathrm{N}_{2} \mathrm{O}$ given alone did not produce important depression of ventricular performance but evidence of a decline in $\mathrm{MVO}_{2}$ was seen. ${ }^{3}$ In healthy man, 40 per cent $\mathrm{N}_{2} \mathrm{O}$ decreased heart rate and cardiac output but raised systemic resistance with no change in blood pressure. ${ }^{2}$ These investigators also documented a rise in plasma norepinephrine in the first 15 minutes of $\mathrm{N}_{2} \mathrm{O}$. Adding 70 per cent $\mathrm{N}_{2} \mathrm{O}$ to steady state halothane anaesthesia in healthy man has given another set of responses: no depression of cardiac output, elevation of vascular resistance, arterial and right atrial pressures. ${ }^{1}$ These investigators concluded their effects to be from sympathetic stimulation and not to a change in oxygen concentration. They also pointed out that their $\mathrm{N}_{2} \mathrm{O}$ studies were done after the initial circulatory adaptation to halothane had occurred. ${ }^{12}$

Maintenance of anaesthesia with halothane and nitrous oxide is common in patients having $C A B G$. In the period after endotrachcal intubation but before the autonomic stimulation of the surgical incision, a fall in blood pressure can occur. We have been concerned whether, during hypotension in such patients, there is a risk of inadequate myocardial oxygenation, or even severe ischaemia and infarction. So we investigated that combination: $\mathrm{N}_{2} \mathrm{O}$ (50 per cent) and a small concentration of halothane ( 0.5 per cent) given at that time, to determine their effects, unassociated with effects of the operation. Fifteen minutes was chosen as the 
time for full effect of $\mathrm{N}_{2} \mathrm{O}$. Compared to the $2-3$ per cent halothane that had been given for at least 15 minutes during induction of anaesthesia, 0.5 per cent inspired halothane along with $\mathrm{N}_{2} \mathrm{O}$, should have produced a lower end-tidal concentration with a diminished halothane effect on the circulation. Unfortunately we did not determine end-tidal concentrations.

We found a 27 per cent reduction in blood pressure, due to decreases in cardiac index (18 per cent), heart rate ( 11 per cent) and systemic resistance ( 15 per cent). The latter decreased in 10 of the 13 patients. Normally this reduction in afterload would be expected to increase stroke volume and cardiac index. However, in our patients, stroke volume did not change. One possible explanation for this, which we saw in our study of nitroglycerine $^{13}$ in these same patients, is that the decrease in afterload is accompainied by a similar decrease in preload (capillary wedge pressure), which offsets the expected increase in stroke volume. Since wedge pressure did not change significantly with $\mathrm{N}_{2} \mathrm{O}$, we cannot invoke that explanation.

Another explanation for the failure of stroke volume to increase with afterload reduction, during $\mathrm{N}_{2} \mathrm{O}$, is a direct myocardial depressing effect, i.e. a reduction in contractility, as others have concluded ${ }^{4,5}$ Figure 1 plots mean stroke work index against mean capillary wedge pressure, plus the individual responses to $\mathrm{N}_{2} \mathrm{O}$ in all 13 patients. The 35 per cent reduction in stroke work with no significant change in mean wedge pressure suggests a shift in the cardiac function curve to one of more depressed function.

Cardiac index fell in our patients mainly because of a slower heart rate, since stroke volume did not change. Thus the systemic haemodynamics suggest a depression of both myocardial inotropic and chronotropic functions.

The reduction in coronary blood flow was likely secondary to a decrease in coronary perfusing pressure (arterial pressure). This may be interpreted in two ways. Firstly, one may say that the myocardium is depressed and does not need as large a coronary flow, i.e. myocardial metabolic needs are decreased. If this were true, there should be a reduced myocardial oxygen extraction, with a consequent increase in oxygen content of coronary sinus blood. That is, the heart worked 35 per cent less, consumed 35 per cent less oxygen $\left(\mathrm{MVO}_{2}\right)$ and coronary flow decreased 35 per cent. However,
VENTRICULAR FUNCTION WITH NITROUS OXIDE

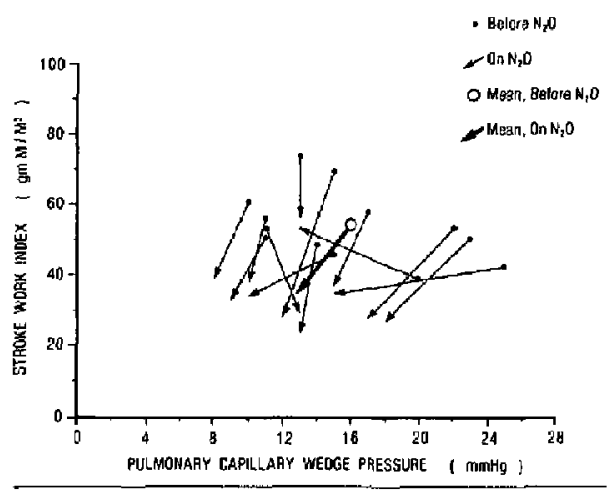

FIGURE 1 The mean capillary wedge pressure is plotted against mean stroke work index for 13 patients, before and during $\mathrm{N}_{2} \mathrm{O}$. In addition, the individual patient responses to $\mathrm{N}_{2} \mathrm{O}$ are shown. Mean stroke work decreased 35 per cent without real change in wedge pressure, suggesting a change to more depressed ventricular function.

that was not the case and another explanation is necessary.

In our patients, CS oxygen content fell during $\mathrm{N}_{2} \mathrm{O}$ in 11 patients, with the mean showing a small but significant decrease. This suggests increased myocardial oxygen extraction. Even though the myocardium is depressed, the reduced coronary flow is not well-tolerated, with regional areas of greater oxygen extraction which is reflected in the smaller CS oxygen content. Supporting this conclusion are the lactate results with an increase in mean lactate concentration of coronary sinus blood. Mean lactate extraction also decreased significantly and in two patients lactate production was seen. These evidences of unbalancing of the myocardial oxygen supply-demand relationship were not accompanied by ST depression.

It must be pointed out that $\mathrm{MVO}_{2}$ is a calculation and not a measurement and the fall in $\mathrm{MVO}_{2}$ was almost entirely due to the decreased coronary flow. Hence in these patients $\mathrm{MVO}_{2}$ does not reflect myocardial metabolic need. The latter is seen from the directly measured indicators of energy metabolism: the oxygen and lactate contents of coronary sinus blood. They revealed myocardia that were heading towards global ischaemia after 15 minutes of $\mathrm{N}_{2} \mathrm{O}$, without surgical stimulation to raise the blood pressure. 
Clur patients appeared to have more pronounced circulatory depression than those of previous studies. ${ }^{1-3}$ No clear explanation exists but a possible factor is the presence of severe obstructive coronary disease, with reduced cardiac reserve. The effects obsirved may not have been solely due to the $\mathrm{N}_{2} \mathrm{O}$ since it alone was tolerated better in another study of coronary patients. ${ }^{3}$ The haemodynamic changes may reflect additive effects of those from halothane.

In summary, fifteen minutes of 50 per cent $\mathrm{N}_{2} \mathrm{O}$, with 0.5 per cent halothane, given for 15 minutes to patients before CABG, caused a significant depression of the circulation and myocardial performance. The hypotension was due to decreased cardiac index, systemic resistance and heart rate. Coronary sinus oxygen content was reduced during $\mathrm{N}_{2} \mathrm{O}$ and coronary sinus lactate content increased, indicating a trend towards compromised myocardial oxygenation. This trend was not identified by ST segment changes.

\section{References}

1 Smith NT, Eger El, II, Stoeiting RK, et al. The cardiovascular and sympathomimetic response to the addition of nitrous oxide to halothane in man. Anesthesiology 1970; 32: 410-21.

2 Eisele JH, Smith NT. Cardiovascular effects of 40 per cent nitrous oxide in man. Anesth Analg 1972; 51: 956-63.

3 Wyrne J, Mann T, Alpert JS, et al. Hemodynamic effects of nitrous oxide administered during cardiac catheterization. JAMA 1980; 243: 1440-3.

4 Lappas DG, Buckley MJ, Laver MB, Daggett WM, Lowenstein $E$. Left ventricular performance and pulmonary circulation following addition of nitrous oxide to morphine during coronary-artery surgery. Anesthesiology 1975; 43: 61-9.

5 Stoelting RK, Gibbs PS, Creasser CW. Peterson, $C$. Hemodynamic and ventilatory responses to fentanyl, fentany'-droperidol, and nitrous oxide in patients with acquired heart disease. Anesthesiology 1975; 42: 319-24.

6 Moffit EA, Sethna DH. Bussell JA, et al. Myocardial metabolism and hemodynamic responses to halochane or morphine ancsthesia for coronary artery surgery. Anesth Analg (In Press).

7 Swan HJ, Ganz W, Forresrer JS, ef al. Catheterization of the heart in man with use of a flow-directed, balloon-tipped catheter. N Engl J Med 1970; 283: 447-50.

8 Ganz W, Tamura K, Marcus HS, et al. Measure- ment of coronary sinus blood flow by continuous thermodilution in man. Circulation 1971; 44: 18195.

9 Yang SS, Bentivoglio LG, Maranhao V, et ai. From cardiac catheterization data to hemodynamic parameters. Philadelphia: F.A. Davis Co. (1972). Pp 3743.

10 Marbach EP, Weil MH. Rapid enzymatic measurements of blood lactate and pyruvate. Clin Chem 1967; 13: 314-25.

11 Thorburn J, Smith G, Vance JP, et al. Effect of nitrous oxide on the cardiovascular system and corcnary circulation in the dog. Br J Anaesth 1979; 51: $937-42$.

12 Eger EI, IJ, Smith NT, Stoelting RK, ef al. Cardiovascular effects of halothane in man. Anesthesiology 1970; 32: 396-409.

13 Sethna DH, Moffier EA, Gray RJ, et al. Intravenous nitroglycerine and myocardial metabolism during anaes thesia in patients undergoing myocardial revascularization. Anesth Analg 1982; 61: 828-33.

\section{Résumé}

Les effets métaboliques et hémodynamiques myacardiaques ont été observés en ajoutant 50 pour cent de protoxyde d'azose a 0.5 pour cent d' halotane d 13 patients avant l' incision chirurgicale de la graffe de l'antère coronaire. Le débit cardiaque et le débit sanguin du sinusal coronaire ficrent déterminés avec la technique de thermodilution suivie de mesures hémodynamiques. Les mesures obtenues 15 minutes apres l'addition de protoxyde d' azote ont démontre une baisse significative de la fréquence cardiaque, de la pression artérielle, de l'index cardiaque, du débil sanguin du sinusal coronaire el de la consommation de l'axygene myocardiaque. On observa une hausse significative du contenu lactate du sinusal coronaire et une baisse significative de 27 a 11 pour cent, de l' extraction lactate myocardique. En conclusion, ces variations circulatoires doivent etre causées par une dépression de la fonction ventriculaire par le protoxyde d'azote. Les myocardies de ces patients souffrant de graves malaises coronaires développèrent une ischémie coronairienne durant la période où ils reçurent 50 pour cent d'oxygène, alors qu'ils étaient hypotensifs. Le protoxyde d'azote ne devrait pas être administré lorsque l' hypotension est présente chez des malades souffrant de malaises coronaires. 